RADOVI

Zavoda za znanstveni rad

HAZU Varaždin
UDK 247.3:262.2(497.523Varaždinske Toplice)

Stručni članak

Professional Paper
ADA VRTULEK GERIĆ

Hrvatski restauratorski zavod, Restauratorski odjel Ludbreg avgeric@h-r-z.hr
Primljeno: 12. 06. 2017.

Prihvaćeno: 08. 11. 2018.

DOI: https://dx.doi.org/10.21857/y6zolb82em

\title{
KONZERVATORSKO-RESTAURATORSKI RADOVI. DVA RELIKVIJARA IZ ŽUPNE CRKVE SV. MARTINA U VARAŽDINSKIM TOPLICAMA
}

\begin{abstract}
Tema ovoga rada su provedeni konzervatorsko-restauratorski radovi na dva moćnika iz župe sv. Martina u Varaždinskim Toplicama iz 18. stoljeća. Moćnici su zaštićena pokretna kulturna baština topličkoga kraja. Radovi su financirani sredstvima Ministarstva kulture, a provedeni su u Restauratorskom centru Hrvatskog restauratorskog zavoda u Ludbregu. Zbog kompleksnosti građe, jer su moćnici sastavljeni od raznovrsnih materijala, trebalo je pri radovima uzeti u obzir sve specifičnosti izvorno upotrijebljenih materijala, vrstu oštećenja te prethodnih intervencija $i$ tome prilagoditi današnje tehnološke mogućnosti restauratorskih metoda.
\end{abstract}

\section{UVOD}

Relikvijari ili moćnici su spremnici u kojima se čuvaju i izlažu na štovanje relikvije, ostaci kršćanskih svetaca i mučenika ili predmeti koji se s njima povezuju. Najčešće su to dijelovi odjeće ili predmet njihove muke. Postoje od 4. stoljeća, čuvaju se u crkvama i samostanima i raznih su oblika, što je najčešće definirano predmetom čuvanja. Mogu biti u obliku medaljona, križeva (stariji), dijela tijela čiji se ostaci u njemu čuvaju ili pak arhitektonskog oblika ili oblika pokaznice. Moćnici mogu biti izrađeni od plemenitih metala (srebra, zlata), ukrašeni dragim kamenjem, ali i drugim materijalima (slonovačom, školjkama, staklom, drvom, papirom, tkaninom i dr.). Česti su u metalu izrađeni reljefi ili oslikani prizori iz Starog i Novog zavjeta, prizori iz života svetaca ili njihova mučeništva te drugi 
kršćanski simboli i dekorativna ornamentika koji uglavnom slijede stilske značajke razdoblja u kojem su nastali, što pridonosi njihovoj velikoj umjetničkoj vrijednosti.

\section{OPIS PREDMETA}

Relikvijari iz župne crkve sv. Martina u Varaždinskim Toplicama danas se čuvaju u župnom dvoru, a još pedesetih godina 20. stoljeća nalazili su se na oltaru sv. Martina, položeni na menzu ispod oltarne slike sv. Martina, lijevo i desno od tabernakula. Relikvijari nepoznatoga autora Mater Christi i A spinis coronatus nastali su potkraj 18. stoljeća. Dimenzije: 61 x 42 × $16 \mathrm{~cm}$.

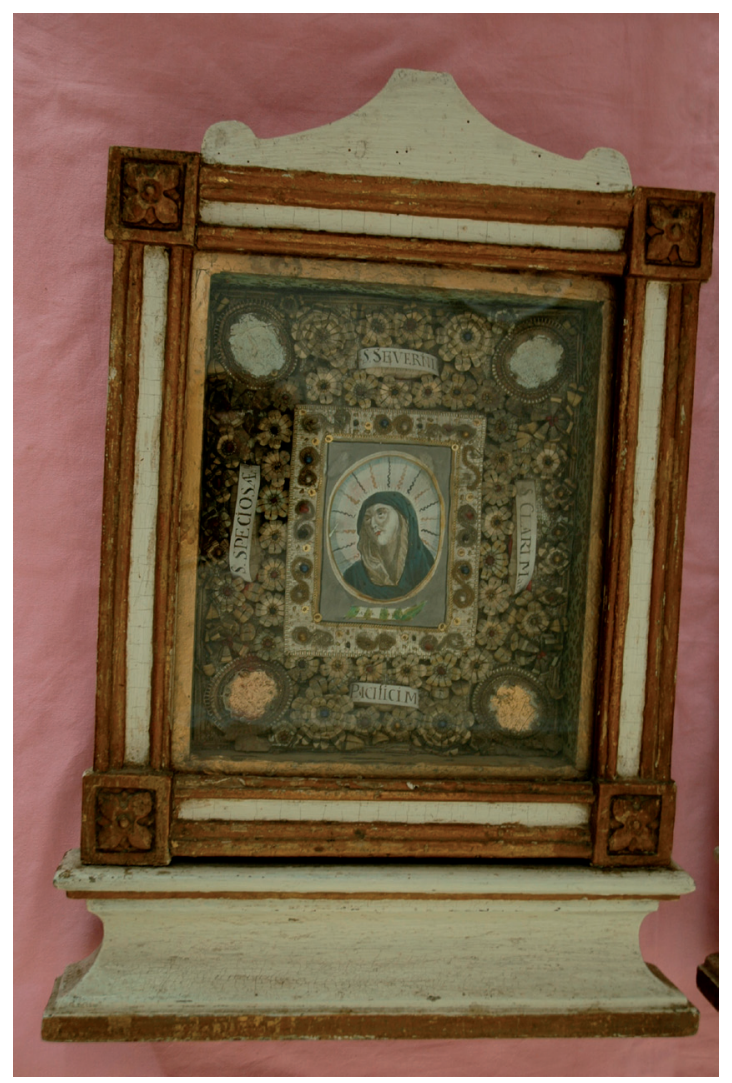

Slika 1. Relikvijar Mater Christi prije radova 


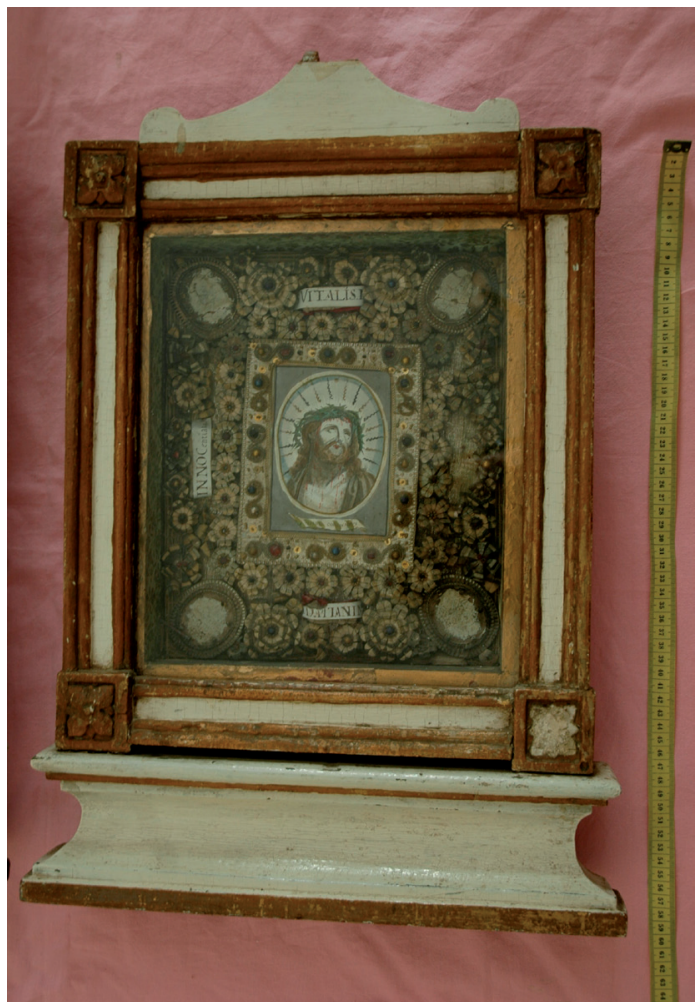

Slika 2. Relikvijar A spinis coronatus prije radova

Okviri moćnika izrađeni su od drveta, koje je s prednje strane rezbareno i polikromirano bijelom bojom te djelomično pozlaćeno. Pozlata se nalazi na rubnim profiliranim dijelovima i rezbarenim ukrasnim elementima (rozetama u kutovima okvira). Okvir je postavljen na niskom drvenom postolju koje je u središnjem dijelu konkavno oblikovano; ima blago istaknut profilirani gornji i donji rub, a sve je polikromirano bijelom bojom. Na vrhu okvira nalazi se trokutasto „krunište" sa stiliziranim volutama koje je nosilo drveni križ.

Unutar ukrasnog okvira smještena je plitka drvena niša, s prednje strane zatvorena staklom. Dno niše obloženo je lame tkaninom. Na tkaninu su gusto aplicirani cvjetni ukrasi od debljeg papira, a latice su ukrašene svilenim i metalnim nitima te perlicama u sredini svakog cvijeta. Raspoznaju se tri vrste cvjetova u plavoj, ružičastoj, bijeloj i žutoj boji. Ukrasi su izvedeni metalnim bujonima, titrankama i raznobojnim perlicama. U sredini moćnika smještena je kasnobarokna minijatura (bakropis koloriran akvarelom) koja prikazuje Madoninu glavu 
(Mater Christi) i Kristovu glavu okrunjenu trnovom krunom (A spinis coronatus). Minijature su uokvirene bijelim okvirom dekoriranim titrankama i metalnim spiralama. U četiri kuta raspoređena su četiri ovalna voštana medaljona s reljefnim prikazima svetaca u ukrasnim okvirima, a između medaljona, paralelno sa stranicama minijature, po četiri relikvije umotane $\mathrm{u}$ tkaninu i prekrivene papirnatom vrpcom s natpisom.

\section{ZATEČENO STANJE}

Drvo okvira bilo je mjestimično crvotočno. Oštećenja su bila vidljiva na rubnim dijelovima s istaknutim profilacijama. Polikromija i bronca na okvirima bile su oštećene i prekrivene slojem prljavštine, a na nekim dijelovima okvira su i nedostajale. S okvira relikvijara $A$ spinis coronatus u donjem desnom kutu nedostajala je jedna rozeta, a na poleđini dio jednog utora i drveni klin te oba klina na poleđini drugog moćnika Mater Christi. Na vrhovima obaju moćnika nisu bili zatečeni križevi.

Unutrašnjost relikvijara bila je vidljivo prašna i onečišćena raznorodnom prljavštinom. Na metalnim dijelovima uočena je oksidativna promjena, lamete su bile djelomično pokidane, a titranke i spirale iskrivljene. Na tkanini kojom su prekrivene moći bila je prljavština i oštećenja nastala djelovanjem svjetla i vlage. Središnje minijature u niši obaju moćnika bile su iskrivljene zbog različitih vanjskih utjecaja, što je vjerojatno uzrokovalo promjenu tona obojenja slikanog dijela.

U relikvijaru A spinis coronatus nedostaje jedan moćnik. U metalnim okvirićima nedostaju medaljoni od voska. Dva donja medaljona u relikvijaru Mater Christi prebojena su „zlatnom“ bojom. Vidljivi su ostaci otopljenog voska na dnu moćnika ispod medaljona. Papirnate vrpce su prašne.

\section{PROVEDENI KONZERVATORSKO-RESTAURATORSKI POSTUPAK}

\section{Drveni ukrasni okviri s postoljem}

Godine 2012. dva moćnika dopremljena su u Restauratorski centar Ludbreg, gdje je u osam tjedana provedena dezinsekcija umjetnina $u$ bezoksi atmosferi s plinovitim dušikom. Za oba moćnika izrađena je fotografska i grafička dokumentacija stanja prije radova. Nakon provedenih povijesno-umjetničkih i konzervatorsko-restauratorskih istraživanja te dobivenih rezultata stratigrafske analize mikropresjeka, sastava pigmenta i veziva, ${ }^{1}$ održane su konzultacije s nadležnim konzervatorima s Konzervatorskog odjela u Varaždinu u svrhu definiranja smjernica za provedbu konzervatorsko-restauratorskih radova.

1 Analize su provedene u Prirodoslovnom laboratoriju Hrvatskog restauratorskog zavoda u Zagrebu. 
S obzirom na donesene zaključke i rezultate istraživanja koji ukazuju na kompleksnost slojeva boje i postojanje izvorne pozlate na profilaciji okvira, na drvenim kućištima relikvijara provedeni su cjeloviti konzervatorsko-restauratorski radovi.

Uklonjena je površinska prljavština i prašina mehaničkim i kemijskim postupkom sa svrhom prezentacije izvornog, olovno bijelog sloja. Odignuti dijelovi slikanog sloja i pozlate podlijepljeni su kožnim tutkalom. Potom je provedena konsolidacija drvenog nosioca, posebno na crvotočnim mjestima, Paraloidom B-72 u acetonu. Uslijedila je rekonstrukcija nedostajućih dijelova (rozete, konstrukcijski elementi i elementi za zatvaranje niša sa stražnje strane).

Na mjestima manjih oštećenja drvenog nosioca provedeno je kitanje celuloznim kitom. Uslijedilo je krediranje i niveliranje te retuš pigmentima, a potom i pozlaćivanje Pudergoldom 23,5 kt uz vezivo. Za retuš na mjestima oštećenja slikanog sloja, kao i za novoizrađene dijelove, bila je primijenjena poentilistička tehnika. Završno lakiranje izvedeno je damarom u terpentinu.

Na mjesta na kojima je pozlata potpuno nedostajala polagani su zlatni listići, nakon čega su patinirani, kako bi se pozlata ujednačila s izvornikom. Druga faza konzervatorsko-restauratorskih radova do dovršenja na kutijama, provedena je 2013. godine u radionici za drvenu polikromiju RCL-a.

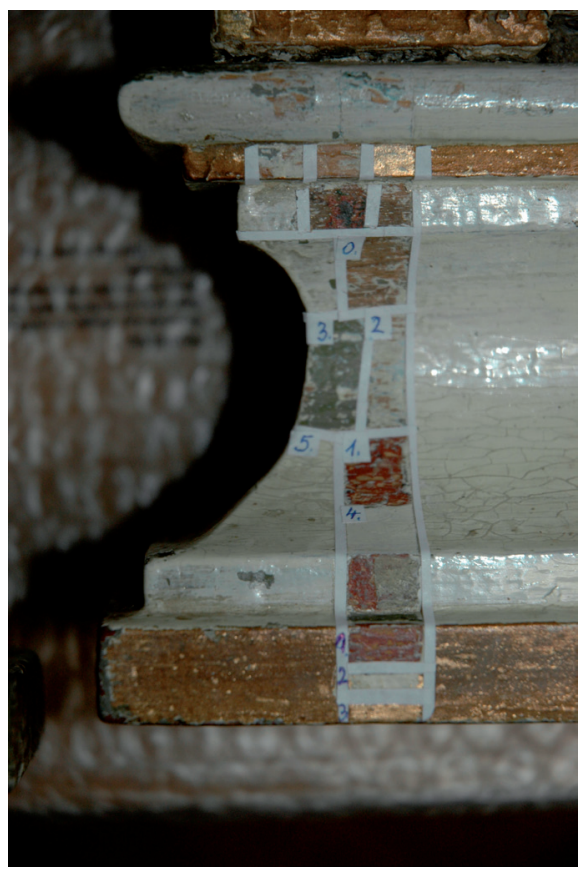

Slika 3. Detalj kučišta relikvijara sonde s vidljivim slojevima boje 


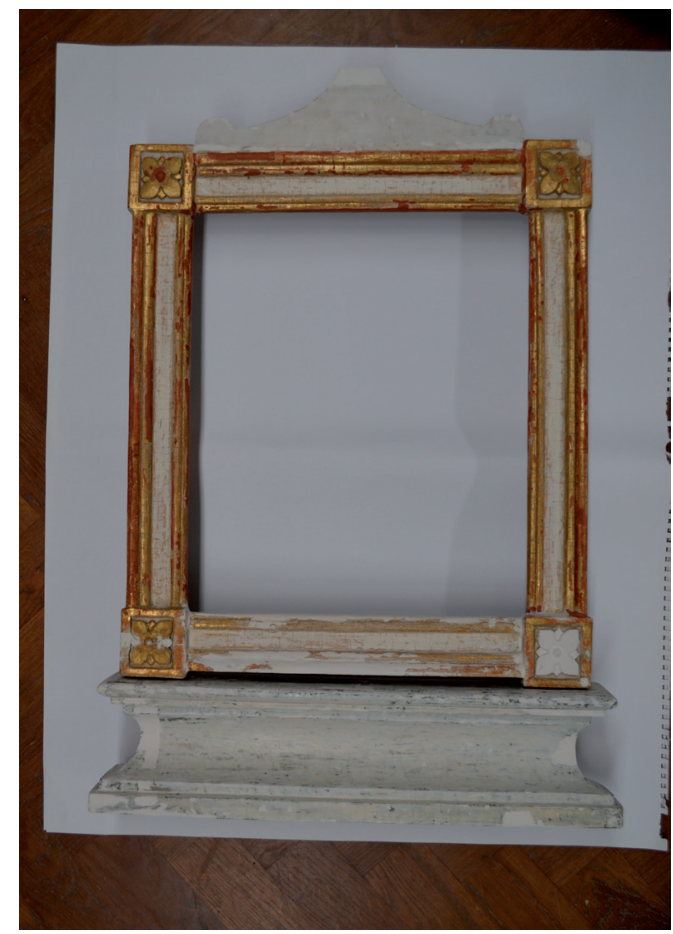

Slika 4. Kučište relikvijara nakon uklanjanja preslika

\section{Unutrašnjost niša}

Za drvene niše s moćima i ukrasima izrađena je fotografska, grafička i pisana dokumentacija stanja prije, tijekom i nakon konzervatorsko-restauratorskih radova. Proveden je suhi postupak čišćenja; muzejskim usisavačem uklonjena je površinska prašina i prljavština. Također je provedeno uzorkovanje sa svrhom identifikacije tekstilnih i metalnih niti te slojeva na medaljonima.

Za tekstilne niti mikroskopijom je utvrđeno da se radi o svilenim tekstilnim nitima. Metalne niti s lame tkanine analizirane su metodom rendgenske fluorescentne spektroskopije (XRF); utvrđeno je da su metalne niti legura bakra i srebra.

Uzorak s medaljona analiziran je metodom tankoslojne kromatografije (dokazana je prisutnost voska), a metodom Fourier transformirane infracrvene spektroskopije (FT-IR) utvrđeno je da uzorak sadrži vosak, najvjerojatnije cerezin, i tragove veziva na bazi proteina. 
Lame tkanina u podlozi, na kojoj su ukrasi, učvršćena je šivanjem po rubnim dijelovima i na mjestima na kojima su odignute metalne lame niti. Metalne i svilene niti, na ukrasima, dodatno su očišćene kistom i učvršćene lijepljenjem na mjestima razdvojenosti, odnosno tamo gdje nije bilo moguće provesti učvršćivanje šivanjem. Papirnate trake s natpisom, kojima su prekrivene moći, izravnate su hladnom parom s pomoću ultrazvučnog raspršivača pare. Mjesta oštećenja i nedostajući dijelovi konsolidirani su japanskim papirom koji je učvršćen celuloznim ljepilom. Nakon sušenja izveden je retuš. Svi dodatni ukrasi po potrebi su učvršćeni šivanjem.

Drvene niše su nakon čišćenja, krediranja i niveliranja retuširane gvaš tehnikom, a vanjski i unutarnji rub papirnate tapete su podlijepljeni. Za moćnike su izrađeni spremnici od beskiselinskog kartona s odgovarajućom popunom. Konzervatorsko-restauratorski radovi provedeni su 2014. godine na Odsjeku za tekstil RCL-a.

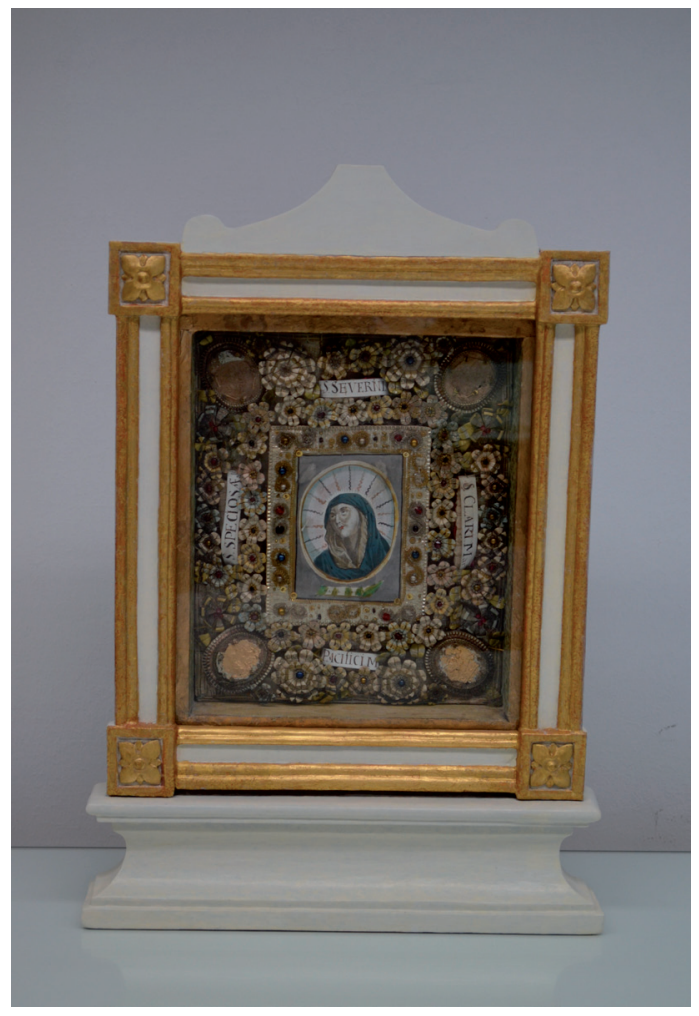

Slika 5. Relikvijar Mater Christi nakon radova 


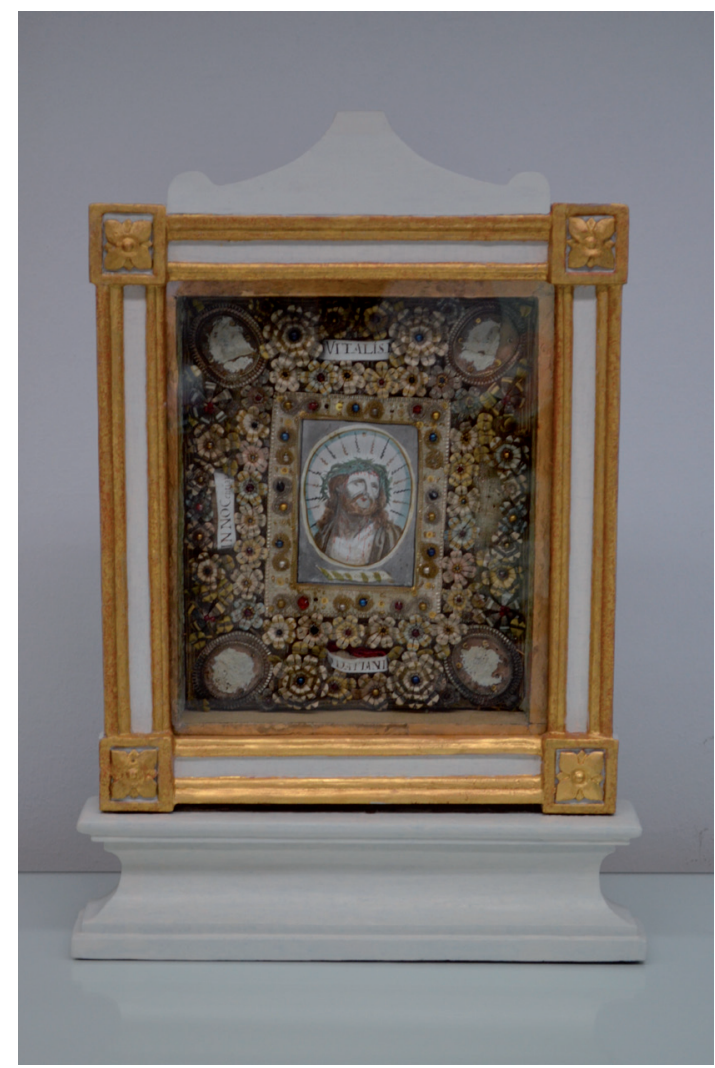

Slika 6. Relikvijar A spinis coronatus nakon radova

Nakon završetka konzervatorsko-restauratorskih radova, moćnici su vraćeni u župni ured rkt. župe sv. Martina u Varaždinskim Toplicama gdje se danas čuvaju.

\section{LITERATURA}

1. „Relikvijar“, Leksikon ikonografije, liturgike i simbolike zapadnog kršćanstva, gl. ur. Anđelko BADURINA, Zagreb, 1990., str. 464, 507.

2. http://www.enciklopedija.hr/natuknica.aspx?id=52387, svibanj 2017.

3. Arhiva radova Restauratorskog centra Hrvatskog restauratorskog zavoda u Ludbregu, 2014., br. dos. 56.3 . 


\section{SAŽETAK \\ KONZERVATORSKO-RESTAURATORSKI RADOVI. DVA RELIKVIJARA IZ ŽUPNE CRKVE SV. MARTINA U VARAŽDINSKIM TOPLICAMA}

Relikvijari ili moćnici su spremnici u kojima se čuvaju i izlažu na štovanje relikvije, ostaci kršćanskih svetaca i mučenika ili predmeti koji se s njima povezuju. Relikvijari Mater Christi i A spinis coronatus, nastali potkraj 18. stoljeća, iz župne crkve sv. Martina u Varaždinskim Toplicama danas se čuvaju u župnom dvoru, a još pedesetih godina 20. stoljeća nalazili su se na oltaru sv. Martina. Trebalo ih je obnoviti i zaštititi zato što su moćnici zaštićena pokretna kulturna baština topličkoga kraja. Radovi su financirani sredstvima Ministarstva kulture, a izvodili su se u Restauratorskom centru Hrvatskog restauratorskog zavoda u Ludbregu. Radovi su bili vrlo kompleksni jer su moćnici sastavljeni od raznovrsnih materijala pa je trebalo uzeti u obzir sve specifičnosti upotrijebljenih materijala, zatečenih oštećenja i prethodnih intervencija i tome prilagoditi današnje tehnološke mogućnosti uobičajenih konzervatorsko-restauratorskih metoda. Proveden je cjelovit konzervatorsko-restauratorski postupak i na drvenim polikromiranim i pozlaćenim kućištima, ali i na bogato ukrašenoj unutrašnjosti. Za moćnike su izrađeni spremnici od beskiselinskog kartona s odgovarajućom popunom te su vraćeni u župni ured rkt. župe sv. Martina u Varaždinskim Toplicama gdje se danas čuvaju.

Ključne riječi: moćnici/relikvijari; zaštićena pokretna kulturna baština; konzervatorsko-restauratorske metode; pohrana. 


\section{CONSERVATION AND RESTORATION WORK. TWO RELIQUARIES FROM THE PARISH CHURCH OF ST. MARTIN IN VARAŽDINSKE TOPLICE}

Reliquaries or shrines are containers used for keeping relics and displaying them for veneration; remains of Christian saints and martyrs or objects linked to them. Reliquaries Mater Christi and A Spinis Coronatus from the parish church of St. Martin in Varažinske Toplice originated in the late $18^{\text {th }}$ century and are kept today in the parish rectory, but until as late as the 1950s were situated at the altar of St. Martin. These shrines are part of the region's protected movable cultural heritage and therefore had to be preserved and restored. The efforts were financed by the Ministry of Culture and carried out at the Croatian Conservation Institute's Ludbreg Conservation Centre. The conservation was rather a complex one, as the reliquaries are composed of diverse materials, whose distinctiveness needed to be taken into account, and bore marks of previous injuries and interventions, which all called for adjustments in the present-day technology of conventional conservation methods. A complete conservation procedure was undertaken on both the wooden polychrome and gilded containers and the richly decorated interiors. Casings were constructed for the shrines from acid-free cardboard with corresponding fillings and they were returned to the office of the RC parish of St. Martin in Varaždinske Toplice, where they are currently kept.

Key Words: shrines / reliquaries; protected movable cultural heritage; conservation and restoration methods; storing. 